\title{
Inhaled nitric oxide improves transpulmonary blood flow and clinical outcomes after prolonged cardiac arrest: a large animal study
}

\author{
Matthias Derwall ${ }^{1 *}$, Andreas Ebeling ${ }^{1}$, Kay Wilhelm Nolte ${ }^{2}$, Joachim Weis ${ }^{2}$, Rolf Rossaint ${ }^{1}$, Fumito Ichinose ${ }^{3}$,
} Christoph $\mathrm{Nix}^{4}$, Michael Fries ${ }^{5}$ and Anne Brücken ${ }^{1}$

\begin{abstract}
Introduction: The probability to achieve a return of spontaneous circulation (ROSC) after cardiac arrest can be improved by optimizing circulation during cardiopulomonary resuscitation using a percutaneous left ventricular assist device (iCPR). Inhaled nitric oxide may facilitate transpulmonary blood flow during iCPR and may therefore improve organ perfusion and outcome.
\end{abstract}

Methods: Ventricular fibrillation was electrically induced in 20 anesthetized male pigs. Animals were left untreated for 10 minutes before iCPR was attempted. Subjects received either 20 ppm of inhaled nitric oxide $(i N O, n=10)$ or 0 ppm iNO (Control, $n=10$ ), simultaneously started with iCPR until 5 hours following ROSC. Animals were weaned from the respirator and followed up for five days using overall performance categories (OPC) and a spatial memory task. On day six, all animals were anesthetized again, and brains were harvested for neurohistopathologic evaluation.

Results: All animals in both groups achieved ROSC. Administration of iNO markedly increased iCPR flow during CPR (iNO: $1.81 \pm 0.30$ vs Control: $1.64 \pm 0.51 \mathrm{~L} / \mathrm{min}, \mathrm{p}<0.001$ ), leading to significantly higher coronary perfusion pressure (CPP) during the 6 minutes of CPR ( $25 \pm 13$ vs $16 \pm 6 \mathrm{mmHg}, \mathrm{p}=0.002$ ). iNO-treated animals showed significantly lower S-100 serum levels thirty minutes post ROSC ( $0.26 \pm 0.09 \mathrm{vs} 0.38 \pm 0.15 \mathrm{ng} / \mathrm{mL}, \mathrm{p}=0.048)$, as well as lower blood glucose levels 120-360 minutes following ROSC. Lower S-100 serum levels were reflected by superior clinical outcome of iNO-treated animals as estimated with OPC ( $3 \pm 2$ vs. $5 \pm 1, p=0.036$ on days 3 to 5 ). Three out of ten iNO-treated, but none of the Control animals were able to successfully participate in the spatial memory task. Neurohistopathological examination of vulnerable cerebral structures revealed a trend towards less cerebral lesions in neocortex, archicortex, and striatum in iNO-treated animals compared to Controls.

Conclusions: In pigs resuscitated with mechanically-assisted CPR from prolonged cardiac arrest, the administration of $20 \mathrm{ppm}$ iNO during and following iCPR improved transpulmonary blood flow, leading to improved clinical neurological outcomes.

\section{Introduction}

Optimizing vital organ blood flow during cardiopulmonary resuscitation $(\mathrm{CPR})$ has been recognized as the key element to increase the rate of return of spontaneous circulation (ROSC, primary survival) and to achieve a favorable long-term neurocognitive outcome (secondary survival) [1].

\footnotetext{
* Correspondence: mderwall@ukaachen.de

'Department of Anesthesiology, University Hospital RWTH Aachen,

Pauwelsstr. 30, 52074 Aachen, Germany

Full list of author information is available at the end of the article
}

In a model of prolonged cardiac arrest we have recently shown that a percutaneous left ventricular assist device (pLVAD, Impella 2.5, Abiomed Inc., Danvers, MA, USA) can double survival [2] when used for cardiopulmonary resuscitation in place of conventional chest compressions. We coined this pLVAD-based approach intraventricular CPR (iCPR), as opposed to conventional chest compression CPR. With iCPR, the left ventricle can be unloaded using a device with similar dimensions to a catheter. The non-pulsatile bloodstream unloads directly into the ascending aorta without any additional 
external circulation. We proposed this technique as a less invasive alternative to extracorporeal CPR (eCPR) using extracorporeal membrane oxygenation (ECMO), as iCPR requires the cannulation of only one femoral vessel with a 13-F sheath introducer rather than two large-bore cannulas when using ECMO.

However, we observed that the achievable flow capacity during ventricular fibrillation (VF) remained lower than expected with roughly $1.36 \pm 0.02 \mathrm{~L} /$ minute, although the iCPR-device is technically capable of delivering a maximum of $2.5 \mathrm{~L} /$ minute. We hypothesized that this flow restriction was primarily due to impaired left ventricular filling, caused by depressed right-to-left transpulmonary blood flow during VF [2].

Inhaled nitric oxide (iNO) was originally developed as a selective pulmonary vasodilator and has been approved since 1999 for the treatment of neonatal hypoxemia with pulmonary hypertension [3]. It is estimated that more than 400,000 Americans have been treated with inhaled $\mathrm{NO}$, with an excellent safety track record [4]. Additionally, iNO has been shown to have systemic effects without causing systemic vasodilation. For example, breathing NO attenuates myocardial ischemia/reperfusion injury in mice [5] and swine [6] and hepatic ischemia/reperfusion injury in patients undergoing liver transplantation [7]. It is also of note that iNO has been shown to improve the maximum flow capacity of a surgically implanted extracorporeal LVAD in a porcine model of hypoxemia-induced pulmonary hypertension and right ventricular failure [8].

Based on these prior observations, we hypothesized that iNO would increase the maximum achievable iCPR flow capacity during resuscitation, and ameliorate the reperfusion injury following $\mathrm{ROSC}$, hence leading to improved clinical outcomes after cardiac arrest. To address this hypothesis, we examined the effects of administering iNO at $20 \mathrm{ppm}$ during and following iCPR in a swine model of prolonged cardiac arrest.
Here, we report that iNO markedly increased the flow capacity of iCPR and improved the neurological outcome after cardiac arrest.

\section{Methods}

A large-animal model of cardiac arrest and CPR was employed, as has been previously described by our group [2, 9-12]. Twenty male domestic pigs at 4 months of age $(44.1 \pm 5.8 \mathrm{~kg})$ were studied. All procedures were conducted in accordance with the principles for the care and use of animals based on the Helsinki Declaration, and approved by the appropriate governmental institution (Landesamt für Natur, Umwelt und Verbraucherschutz NRW, LANUV, Recklinghausen, Germany).

\section{General preparation}

Following induction of anesthesia, animals were intubated and equipped with percutaneous catheters and sheath introducers in femoral arteries and veins before a 5-French pacing catheter was placed in the cephalic vein. Animals were then equipped with a modified Impella 2.5 (iCPR-device) with a shortened angled cannula as described in [2]. All animals received two intravenous (IV) injections of $5,000 \mathrm{IU}$ heparin and $1.5 \mathrm{~g}$ of cefuroxime to prevent blood clotting and wound infections.

\section{Experimental protocol}

Please see Fig. 1 for a comprehensive overview of the experimental procedure.

Following the general preparation, but before induction of cardiac arrest, animals were randomized to either receive $20 \mathrm{ppm}$ of iNO $(\mathrm{n}=10)$ or nitrogen $(\mathrm{n}=10$, control), using the closed envelope method. The respective gas was applied using a human-grade intensive care respirator (Servo Ventilator 300A, Siemens, Munich, Germany).

Cardiac arrest was electrically induced, and confirmed by the onset of VF and a rapid decrease in mean arterial
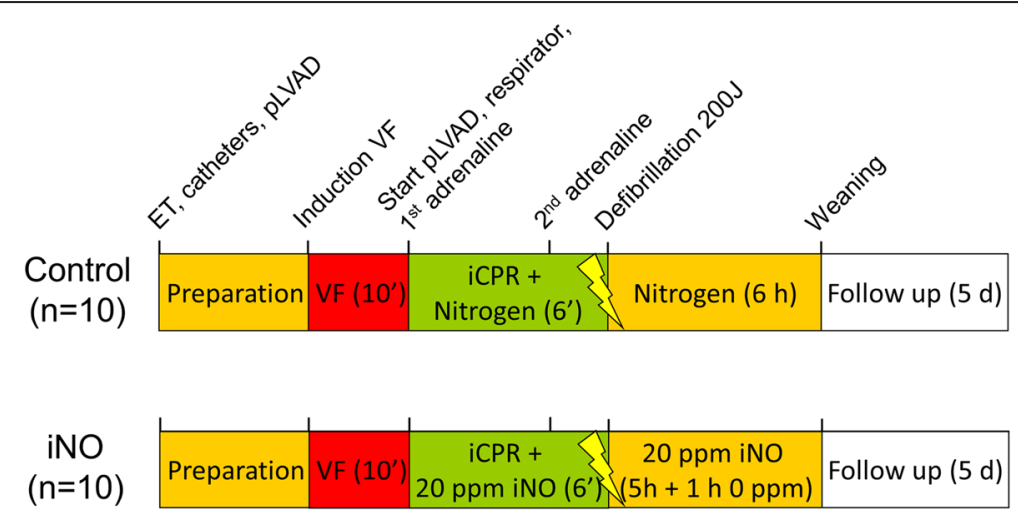

Fig. 1 Experimental procedure. Flowchart depicting the sequence of actions taken in the experiments comparing animals treated with $20 \mathrm{ppm}$ inhaled nitric oxide (iNO, $n=10)$ to control $(n=10)$. Note that no external chest compressions were applied during any stage of the experiment. ET endotracheal tube, pLVAD percutaneous left ventricular assist device, VF ventricular fibrillation 
pressure (MAP). Simultaneously, mechanical ventilation was discontinued and the animal left untreated for 10 minutes. Then, iCPR-treatment was initiated by activating the previously implanted pLVAD at the maximum possible flow. No additional chest compressions were delivered during any phase of the experiment. To achieve maximum flow, the Impella controller was set to Auto-mode, in which the software automatically determines the maximum flow capacity by evaluating the motor current to identify wall suction. Simultaneously with the start of the PLVAD, ventilation was restarted with an inspired oxygen fraction $\left(\mathrm{FiO}_{2}\right)$ of 1.0, blended with either $20 \mathrm{ppm}$ of iNO or nitrogen, before animals received a bolus dose of $30 \mu \mathrm{g} / \mathrm{kg}$ adrenaline and Ringer's solution at a rate of $100 \mathrm{~mL} /$ minute. A second dose of adrenaline was administered 4 minutes and 30 seconds after the start of resuscitation.

After six minutes of iCPR, defibrillation was attempted with up to two 200-J biphasic waveform shocks (MSeries CCT; Zoll Medical Corporation, Chelmsford, MA, USA). If an organized rhythm with an MAP $>60 \mathrm{mmHg}$ persisted for 5 minutes, the animal was regarded as successfully resuscitated. If VF was not successfully reversed, one minute of iCPR preceded the delivery of another sequence of up to two shocks.

After successful resuscitation, anesthesia was continued, and animals were monitored for 6 hours. In the iNO group, animals were ventilated with $\mathrm{NO}$ at $20 \mathrm{ppm}$ for up to 5 hours after ROSC. Thirty minutes following ROSC, FiO2 was reduced to 0.3 in both groups. After the 6-hour observation period, anesthesia was stopped and animals weaned from the respirator as previously described in detail [2]. Following the removal of all foreign materials, animals were brought to their cages and clinically observed for up to 5 days.

\section{Measurements}

Blood pressure, heart rate, and EKG (electrocardiogram) readings were continuously measured and digitally recorded. Pulmonary artery and pulmonary capillary wedge pressure (PCWP) were measured using a hexalumen Swan-Ganz catheter (744HF75, Edwards Lifesciences, Irvine, CA, USA) and a Vigilance monitor. Cerebral oxymetry was performed and tracked using the INVOS 5100c cerebral oxymeter and appropriate INVOS cerebral oxymetry adult sensors (both Covidien, Dublin, Ireland). Coronary perfusion pressure (CPP) was calculated by subtracting the mid-diastolic right atrial pressure from the mid-diastolic aortic pressure [13]. However, due to the non-pulsatile flow generated by the pLVAD, CPP was calculated by subtracting the mean right atrial pressure from mean aortic pressure during CPR. Pulmonary vascular resistance was calculated using equation (1) as follows:

$$
\frac{80 \times(M P A P-P C W P)}{\text { Cardiac Output }},
$$

where MPAP is the mean pulmonary artery pressure and PCWP the pulmonary capillary wedge pressure.

However, during iCPR, PCWP and cardiac output were not available for technical reasons. PCWP was therefore omitted and cardiac output replaced by pLVAD flow, resulting in equation (2). Calculating pulmonary vascular resistance (PVR) without accounting for PCWP is frequently referred to as total PVR [14]. Equation (2) is as follows:

$$
\frac{80 \times(M P A P)}{i C P R \text { flow }}
$$

The arterial oxygen and carbon dioxide tension $\left(\mathrm{P}_{\mathrm{a}} \mathrm{O}_{2}\right.$ and $\mathrm{P}_{\mathrm{a}} \mathrm{CO}_{2}$, respectively), blood glucose levels, and lactate levels were measured using a point-of-care blood gas analyzer (ABL 510; Radiometer, Copenhagen, Denmark). Blood samples were obtained at baseline (i.e., 5 minutes before cardiac arrest) and every hour for 6 hours after ROSC. At the same time points, serum samples to determine astroglial S-100 protein levels (to quantify neuronal cell death) were obtained and promptly frozen to allow for measurements at a later time using a commercially available ELISA kit (YK150, BioTrend, Cologne, Germany).

\section{Post-arrest care}

Following the resuscitation procedure and weaning from the respirator, animals were brought to their cages and monitored permanently by research staff. Analgesia was provided by an intramuscular injection of $0.1 \mathrm{mg} / \mathrm{kg}$ buprenorphine if tachypnea ( $>20 /$ minutes) was observed or an animal seemed agitated. Chow and water were offered by gentle spoon-feeding in cases where animals exhibited inadequate food intake. If an animal was not able to swallow, Ringer's solution was administered intravenously at a rate of $10 \mathrm{~mL} / \mathrm{kg} / \mathrm{h}$. Animals that did not improve with this protocol and were not able to stand up and walk within 48 hours were euthanized by intravenous injection of a lethal dose of pentobarbital.

Euthanized animals were perfused with $4 \%$ paraformaldehyde and brains carefully harvested and histopathologically analyzed as described in [12]. All animals underwent systematic necropsy of the thoracic and abdominal cavities to identify injuries to the chest or thoracic or visceral organs.

\section{Neurological testing}

On each day post-arrest, animals were evaluated using overall performance categories (OPC), as described in previous studies $[10,11]$. In brief, the test consists of five items representing the degree of impairment as follows: OPC 1, normal, no obvious neurologic damage; OPC 2, 
moderate disability, animals being conscious and aware, standing but unable to walk; OPC 3, severe disability, animals being neither fully aware nor unconscious, but with reaction to pain and auditory stimuli, not able to stand or walk; OPC 4, coma; and OPC 5, death or brain death. In animals receiving buprenorphine as part of the post-arrest care protocol, an adequate interval ( $>4$ hours) was allowed to elapse before neurological testing was performed.

In addition, animals were challenged with a visual spatial memory task, described previously in detail in [10]. In this test, animals are trained individually to obtain food from three feeding troughs in an area separated from their housing. Following acclimatization with the setting, the lids of two of the containers are locked, and the animal is expected to learn that one trough can still be opened, and to remember this very container. To quantify the performance, time elapsed from entering the separated area until food is obtained is recorded.

\section{Statistical analysis}

All data are expressed as the mean \pm SD unless stated otherwise. Normal distribution of the data was confirmed using the Kolmogorov-Smirnov test. For group comparisons of continuous variables, repeated measures analysis of variance (ANOVA) was employed followed by the pairwise Student's t test at given time points, adjusted for multiple comparisons by Bonferroni's method in cases where significant differences were observed. Where appropriate, Fisher's exact test and the MannWhitney $U$ test was performed to compare categorical variables. In all cases, $p \leq 0.05$ was considered to indicate statistical significance.

\section{Results}

Inhaled NO increased pLVAD flow and coronary perfusion pressure during $\mathrm{iCPR}$

Hemodynamics and blood gas results did not differ between groups before iCPR was initiated (Table 1). Group assignment did not influence time to ROSC (iNO vs. Control: $16.5 \pm 0.7$ vs. minutes, $p=0.214$ ), amount of adrenaline given $(2.2 \pm 0.6$ vs $2.0 \pm 0.1 \mathrm{mg}, p=0.382)$ or the number of shocks $(2.6 \pm 1.8$ vs $3.5 \pm 2.6, p=0.387)$.

During iCPR, iNO treatment allowed for higher average pump flow compared to control $(1.81 \pm 0.30 \mathrm{vs}$ $1.64 \pm 0.51 \mathrm{~L} /$ minute, $p<0.001$, see Fig. $2 \mathrm{a}$ ), translating into higher CPP values during the 6 minutes of iCPR before the first defibrillation was attempted ( $25 \pm 13$ vs $16 \pm$ $6 \mathrm{mmHg}, \mathrm{p}=0.002$, Fig. 2b). iNO-treatment did not affect MPAP during iCPR ( $12 \pm 6$ vs $13 \pm 3 \mathrm{mmHg}, p=0.284)$.

Table 1 Hemodynamics and blood gas data

\begin{tabular}{|c|c|c|c|c|c|c|}
\hline & & $B L$ & PR 10 & PR 30 & PR 60 & PR 360 \\
\hline & & $\mathrm{iNO} n=10$ & $\mathrm{iNO} n=10$ & $\mathrm{iNO} n=10$ & $\mathrm{iNO} n=10$ & $\mathrm{iNO} n=10$ \\
\hline & & Control $n=10$ & Control $n=10$ & Control $n=10$ & Control $n=10$ & Control $n=10$ \\
\hline \multirow[t]{2}{*}{$\mathrm{HR}$ (bpm) } & iNO & $89 \pm 16$ & $156 \pm 47$ & $130 \pm 56$ & $111 \pm 22$ & $104 \pm 19$ \\
\hline & Cont & $81 \pm 12$ & $192 \pm 33$ & $164 \pm 33$ & $124 \pm 24$ & $102 \pm 23$ \\
\hline \multirow[t]{2}{*}{ MAP (mmHg) } & iNO & $91 \pm 13$ & $89 \pm 8^{*}$ & $72 \pm 15$ & $70 \pm 14$ & $83 \pm 6^{*}$ \\
\hline & Cont & $94 \pm 9$ & $104 \pm 14$ & $81 \pm 12$ & $78 \pm 9$ & $92 \pm 10$ \\
\hline \multirow[t]{2}{*}{ CO (L/minute) } & iNO & $5.0 \pm 2.1$ & $7.8 \pm 2.5$ & $4.3 \pm 1.8$ & $3.8 \pm 1.5$ & $4.6 \pm 0.9$ \\
\hline & Cont & $5.2 \pm 0.9$ & $9.0 \pm 1.8$ & $5.4 \pm 1.4$ & $3.6 \pm 0.7$ & $6.0 \pm 2.2$ \\
\hline \multirow[t]{2}{*}{ MPAP (mmHg) } & iNO & $14 \pm 44$ & $15 \pm 4^{*}$ & $13 \pm 3$ & $12 \pm 3^{*}$ & $19 \pm 5$ \\
\hline & Cont & $16 \pm 4$ & $21 \pm 3$ & $16 \pm 4$ & $18 \pm 4$ & $20 \pm 4$ \\
\hline \multirow[t]{2}{*}{$\mathrm{P}_{\mathrm{a}} \mathrm{O}_{2}(\mathrm{mmHg})$} & iNO & $139 \pm 5$ & $434 \pm 92^{*}$ & $329 \pm 199$ & $136 \pm 6$ & $123 \pm 18$ \\
\hline & Cont & $140 \pm 6$ & $504 \pm 68$ & $454 \pm 174$ & $138 \pm 8$ & $135 \pm 13$ \\
\hline \multirow[t]{2}{*}{$\mathrm{P}_{\mathrm{a}} \mathrm{CO}_{2}(\mathrm{mmHg})$} & iNO & $42 \pm 4$ & $40 \pm 2$ & $38 \pm 3$ & $39 \pm 4$ & $43 \pm 4$ \\
\hline & Cont & $41 \pm 3$ & $44 \pm 5$ & $39 \pm 4$ & $38 \pm 4$ & $42 \pm 5$ \\
\hline \multirow[t]{2}{*}{ Lactate (mmol/L) } & iNO & $1.4 \pm 0.7$ & $6.8 \pm 1.4$ & $6.9 \pm 1.5$ & $5.9 \pm 1.9$ & $0.7 \pm 0.2$ \\
\hline & Cont & $1.4 \pm 0.2$ & $7.5 \pm 1.2$ & $7.3 \pm 1.4$ & $5.7 \pm 1.1$ & $1.0 \pm 0.5$ \\
\hline \multirow[t]{2}{*}{ Glucose (mmol/L) } & iNO & $118 \pm 16$ & $277 \pm 19$ & $252 \pm 25$ & $234 \pm 31$ & $117 \pm 17^{*}$ \\
\hline & Cont & $127 \pm 13$ & $294 \pm 33$ & $274 \pm 24$ & $251 \pm 29$ & $132 \pm 12$ \\
\hline \multirow[t]{2}{*}{$\mathrm{pH}$} & iNO & $7.47 \pm 0.02$ & $7.35 \pm 0.03^{*}$ & $7.40 \pm 0.06$ & $7.41 \pm 0.06$ & $7.46 \pm 0.03$ \\
\hline & Cont & $7.47 \pm 0.04$ & $7.30 \pm 0.04$ & $7.37 \pm 0.04$ & $7.42 \pm 0.04$ & $7.47 \pm 0.04$ \\
\hline
\end{tabular}

Hemodynamic and blood gas data in 20 pigs, treated either with 20 ppm of inhaled nitric oxide (iNO; $\mathrm{n}=10)$ or $0 \mathrm{ppm}$ iNO (Control; $\mathrm{n}=10$ ) at baseline (BL) or 10 (PR10), 30 (PR30), 60 (PR60), or 360 (PR360) minutes after return of spontaneous circulation. Results are presented as mean \pm SD; ${ }^{*} p \leq 0.05$ for iNO vs Control. $H R$ heart rate, MAP mean arterial pressure, $\mathrm{CO}$ cardiac output, MPAP mean pulmonary artery pressure, $P_{a} \mathrm{O}_{2}$ arterial oxygen tension, $P_{a} C \mathrm{O}_{2}$ arterial carbon dioxide tension 
However, we observed significantly lower MPAP in animals that breathed $\mathrm{NO}$ than those breathing nitrogen as soon as 3 minutes after the ROSC $(17 \pm 3$ vs $23 \pm 5$ $\mathrm{mmHg}, p=0.003)$. This difference in MPAP continued until iNO was stopped at 5 hours after ROSC (Fig. 2c). Calculated total PVR appeared to be effectively lowered, beginning 3 minutes after the start of iNO treatment during CPR (Fig. 2d).

\section{NO breathing increased cerebral oxygenation without increasing cardiac output after ROSC}

Breathing NO increased cerebral oxygenation at 2 hours after ROSC $(56.5 \pm 4.7$ vs $47.2 \pm 8.6 \%, p=0.043$; Fig. 3a). End-tidal $\mathrm{CO}_{2}$ values as a measure of the quality of circulation trended towards higher numbers with iNO treatment than in controls. However, this was not statistically significant at any time point during CPR. Inhaled NO did not affect cardiac output in the post-ROSC period either (Table 1).

Inhaled NO suppressed the increase of glucose after ROSC Blood glucose levels were not different at baseline and up to one hour after ROSC. However, animals treated with iNO had significantly lower blood glucose values compared to controls, starting from 2 hours after the start of iNO until 6 hours after the CPR procedure (Fig. 3b).

\section{NO breathing improved neurological outcome after cardiac arrest}

All animals in both groups achieved ROSC. However, while five animals that breathed NO survived until day 5 post CPR, only one control animal survived until the end of the observation period ( $p=0.141$, Fig. 4a). While three iNO-treated animals were able to participate in the spatial memory task on the first day post CPR, only one of the controls were able to do so (Table 2). Nine control and five iNO-treated animals had to be euthanized prematurely due to severe neurological deficits. This translated into significantly better score values for iNO-treated animals in the outcome assessment with OPC on days $3-5$ post CPR ( $3 \pm 2$ vs $5 \pm 1, p=0.036$ on days $3-5$; Fig. 4 b).

The favorable neurological outcome was associated with lower S-100 serum levels in iNO-treated animals, detected as early as 30 minutes post ROSC $(0.26 \pm 0.09$ vs $0.38 \pm 0.15 \mathrm{ng} / \mathrm{mL}, p=0.048$; Fig. $4 \mathrm{c}$ ).

Neurohistopathological examination of vulnerable cerebral structures prone to ischemia-reperfusion injury trended towards fewer cerebral lesions in iNO-treated vs control animals euthanized on day 1 following the CPR procedure (neocortex: $2.5 \pm 1.7$ vs $3.7 \pm 2.3 \mathrm{AU}, p=$ 0.192 ; archicortex $5.8 \pm 1.5$ vs $8.4 \pm 4.5 \mathrm{AU}, p=0.142$; striatum $10.3 \pm 1.7$ vs $11.1 \pm 1.2 \mathrm{AU}, \mathrm{p}=0.168$; Fig. $4 \mathrm{~d}$ ). Furthermore, the single control animal surviving until
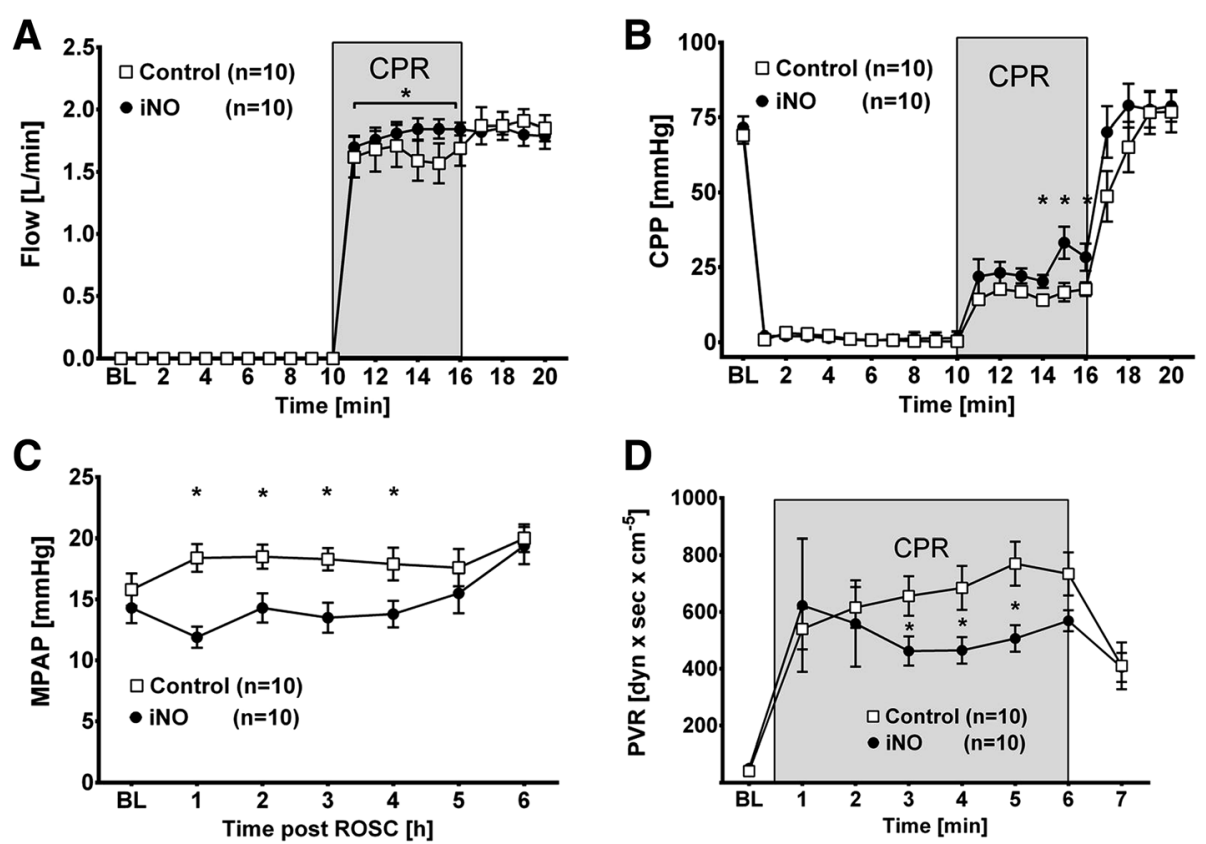

Fig. 2 Inhaled nitric oxide (iNO) impacts hemodynamics during and after cardiac arrest. Comparison of animals treated with $20 \mathrm{ppm}$ iNO $(n=10)$ or Control $(n=10)$. Mean \pm standard error of the mean: ${ }^{*} p \leq 0.05$, comparing iNO to Control. BL baseline (i.e., 5 minutes prior to cardiac arrest), $C P R$ cardiopulmonary resuscitation. a Pump flow of the intravascular cardiopulmonary resuscitation device. $\mathbf{b}$ Calculated coronary perfusion pressure (CPP). c Mean pulmonary artery pressure (MPAP) measured at BL and 1, 2, 3, 4, 5, and 6 hours after return of spontaneous circulation (ROSC). $\mathbf{d}$ Calculated pulmonary vascular resistance (PVR) before (BL), during (1-6 minutes), and following cardiac arrest and resuscitation (7 minutes). Time indicates period since start of CPR. The 10-minute period of untreated ventricular fibrillation preceding CPR was omitted for clarity 

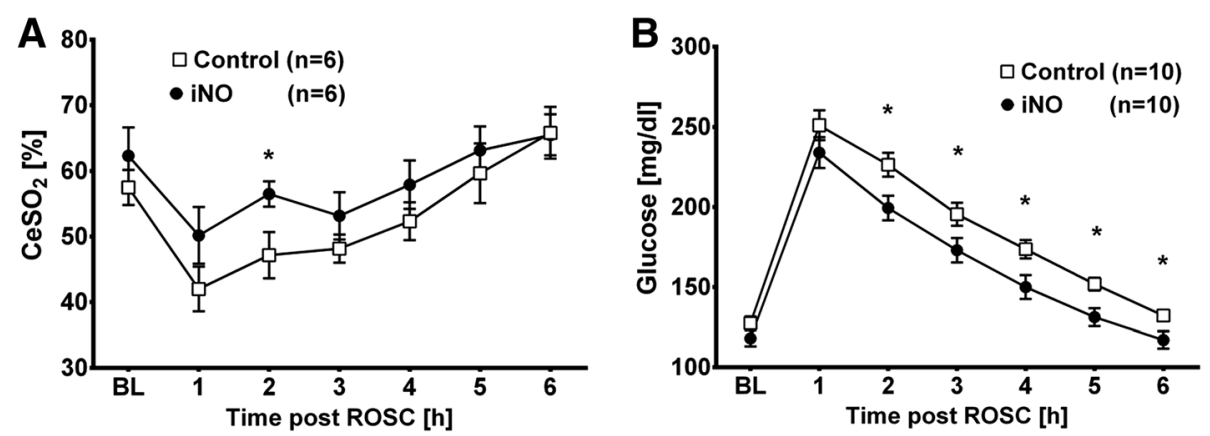

Fig. 3 Inhaled nitric oxide (iNO) improves cerebral oxygenation and suppresses the increase of glucose after return of spontaneous circulation (ROSC). Comparison of animals treated with $20 \mathrm{ppm}$ iNO $(n=10)$ or Control $(n=10)$. Mean \pm standard error of the mean: ${ }^{*} p \leq 0.05$, comparing iNO to Control. $\mathrm{BL}$ baseline (i.e., 5 minutes prior to cardiac arrest). a Cerebral oxygenation $\left(\mathrm{CeSO}_{2}\right)$ was estimated using transcutaneous spectroscopy using near-infrared light. Due to limited availability during experiments, values were estimated in 6 animals per group. b Serum glucose levels before and after cardiac arrest and resuscitation

day 5 exhibited greater neuroistopathological damage than did the five iNO-treated animals that survived thus far (neocortex: $4.6 \pm 1.7$ vs $7.0 \mathrm{AU}$; archicortex $10.2 \pm$ 4.8 vs $13.0 \mathrm{AU}$; striatum $12.6 \pm 6.5$ vs $12.0 \mathrm{AU}$ ). Of note, the neurohistopathological damage scores appeared to rise over time in both groups, suggesting a secondary injury of the cerebral tissue following the acute ischemic insult during cardiac arrest. Systematic necropsy of the animals revealed no macroscopic trauma to heart, valves, or major vessels.
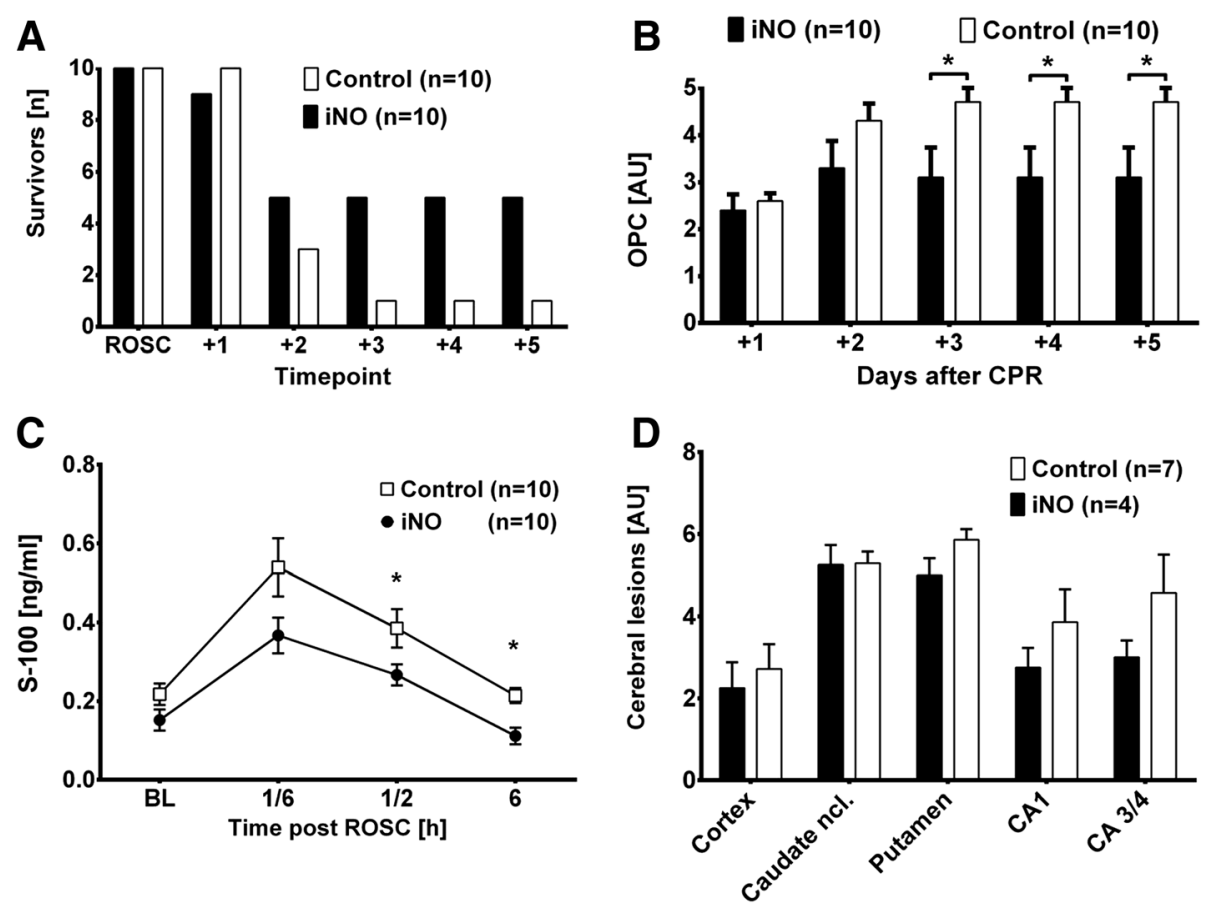

Fig. 4 Inhaled nitric oxide (iNO) impacts the outcome after cardiac arrest. Comparison of animals treated with $20 \mathrm{ppm}$ iNO $(\mathrm{n}=10)$ or Control $(\mathrm{n}=10)$. Mean \pm standard error of the mean: ${ }^{*} p \leq 0.05$, comparing iNO to Control. ROSC return of spontaneous circulation, $B L$ baseline (i.e., 5 minutes prior to cardiac arrest), AU arbitrary units. a Number of animals that achieved ROSC or were alive on days $1(+1), 2(+2), 3(+3), 4(+4)$ or $5(+5)$ post cardiopulmonary resuscitation (CPR). b Overall performance categories (OPC): OPC 1, normal, no obvious neurologic damage; OPC 2, moderate disability, animals being conscious and aware, standing but unable to walk; OPC 3, severe disability; animals being neither fully aware nor unconscious, but with reaction to pain and auditory stimuli, not able to stand or walk; OPC 4, coma; OPC 5, death or brain death. c S-100 protein levels measured at BL, 10 minutes (1/6), 30 minutes (1/2), or 6 hours after ROSC. S-100 serum levels were employed as an indicator of the degree of cerebral ischemia-reperfusion injury. $\mathbf{d}$ Results from the blinded neurohistopathological evaluation in animals euthanized 24 hours after ROSC due to their inability to rise 
Table 2 Spatial memory task

\begin{tabular}{|c|c|c|c|c|c|c|}
\hline & \multicolumn{3}{|l|}{ iNO } & \multicolumn{3}{|c|}{ Control } \\
\hline & $\begin{array}{l}\text { Alive } \\
\text { (n) }\end{array}$ & $\begin{array}{c}\text { Testable } \\
\text { (n) }\end{array}$ & $\begin{array}{l}\text { Time } \\
\text { (s) }\end{array}$ & $\begin{array}{l}\text { Alive } \\
\text { (n) }\end{array}$ & $\begin{array}{c}\text { Testable } \\
\text { (n) }\end{array}$ & $\begin{array}{l}\text { Time } \\
(\mathrm{s})\end{array}$ \\
\hline \multicolumn{7}{|c|}{ Day } \\
\hline-5 & 10 & 10 & $475 \pm 233$ & 10 & 10 & $498 \pm 188$ \\
\hline-4 & 10 & 10 & $338 \pm 249$ & 10 & 10 & $162 \pm 251$ \\
\hline-3 & 10 & 10 & $35 \pm 36$ & 10 & 10 & $141 \pm 261$ \\
\hline-2 & 10 & 10 & $9 \pm 5$ & 10 & 10 & $74 \pm 197$ \\
\hline-1 & 10 & 10 & $7 \pm 2$ & 10 & 10 & $13 \pm 11$ \\
\hline \multicolumn{7}{|c|}{ CPR } \\
\hline+1 & 9 & 3 & $406 \pm 336$ & 10 & 0 & - \\
\hline+2 & 5 & 3 & $402 \pm 344$ & 3 & 1 & $600 \pm 0$ \\
\hline+3 & 5 & 3 & $403 \pm 341$ & 1 & 1 & $600 \pm 0$ \\
\hline+4 & 5 & 3 & $119 \pm 115$ & 1 & 1 & $600 \pm 0$ \\
\hline+5 & 5 & 3 & $91 \pm 126$ & 1 & 1 & $600 \pm 0$ \\
\hline
\end{tabular}

Performance of the tested animals in a spatial memory task before (Days -5 to -1 ) and after (Days +1 to +5 ) cardiac arrest and cardiopulmonary resuscitation (CPR). Time in seconds is provided as mean \pm SD. The ability to participate in the test was defined as the ability to stand and walk in conjunction with physiologic searching behavior. Up to 600 seconds were allowed to complete the test. iNO inhaled nitric oxide

\section{Discussion}

Here we show for the first time, that iNO enhances transpulmonary blood flow during resuscitation with a percutaneous axial left ventricular assist device. Improved cerebral perfusion during $\mathrm{iCPR}$ and after ROSC was associated with improved cerebral oxygenation and with lower serum levels of S-100 protein. In addition we observed a significant impact of iNO on glucose serum levels. These beneficial hemodynamic and metabolic effects translated into improved clinical outcomes in the first 5 days following resuscitation.

\section{Improving hemodynamics with iNO during extracorporeal life support and iCPR}

Recently, Lovich and colleagues have shown that iNO is capable of improving the maximum flow capacity of a surgically implanted extracorporeal LVAD in a porcine model of hypoxemia-induced pulmonary hypertension and right ventricular failure [8]. In their study, $20 \mathrm{ppm}$ of iNO increased the maximum achievable pump speed, flow, cardiac output, and left ventricular diameter. iNO reduced pulmonary vascular resistance, right ventricular (RV) afterload and thereby facilitated transpulmonary blood flow. These observations are consistent with previous findings in a small randomized double-blind clinical trial in which iNO was shown to decrease pulmonary arterial pressure (PAP) and increase LVAD flow [15]. For the first time, our study extends the concept of improving transpulmonary blood flow with iNO to the condition of LVAD support during CPR after prolonged cardiac arrest.
Pulmonary artery pressure is known to be elevated during conventional cardiac arrest and resuscitation, with elevated pulmonary vascular resistance being the primary cause $[16,17]$. The intermittent high intrathoracic pressure during external chest compressions in concert with hypoxic pulmonary vasoconstriction may limit right-to-left transpulmonary bloodflow during CPR. We have previously shown that omitting chest compressions during iCPR reduces pulmonary blood pressure, but still does not solve the problem of limited transpulmonary blood flow [2]. As iNO is a potent local vasodilator, one could expect a further lowering of the mean pulmonary artery pressure during CPR. However, this was not the case in our investigation, as PAP was only reduced by iNO after ROSC, but not during iCPR. In contrast, we saw a pronounced lowering of pulmonary vascular resistance during iCPR. As the pLVAD controller increased flow as soon as the pulmonary vascular tone was lowered, MPAP remained constant. The improved pLVAD flow during iCPR then translated into higher mean arterial pressures, which in turn led to improved calculated CPP during resuscitation. This observation suggests that, when performing iCPR, MPAP may not be a reliable indicator of effective pulmonary vasodilation.

\section{Regional and systemic effects of iNO during and after cardiac arrest}

Alterations in organ perfusion by iNO do not appear to be the sole factor for influencing the clinical outcome, because iNO did not affect serum lactate levels, a marker for poor tissue perfusion, at any point during the investigation. Nonetheless, we still observed a pronounced reduction in S-100 serum protein, a proposed marker for the degree of cerebral injury $[18,19]$. Besides its beneficial effects on iCPR performance and hemodynamics, iNOtreated animals exhibited a significantly better clinical outcome compared to control animals in our study. These results corroborate findings from others, and for the first time extend them to a large-animal model of cardiac arrest and CPR. Minamishima and colleagues found that in mice, breathing NO starting one hour after ROSC markedly improved long-term neurological outcomes and survival after 7.5 minutes of cardiac arrest, without causing systemic hypotension [20]. Neuroprotective effects of iNO have been subsequently confirmed by several groups that showed that inhaled NO decreased brain stroke volume in mice, rats, and sheep [21-23]. Besides its neuroprotective effects, several researches have reported cardioprotective effects of iNO in mice and pigs [24-26]. The ability of iNO to reduce I/R (ischemia/reperfusion) injury was subsequently reproduced in proof-of-principle human studies [7, 27]. Hence, our current study provides further support for the organoprotective properties of 
iNO at clinically relevant concentrations, when given during and after cardiac arrest.

The mechanisms through which iNO exerts its protective effects in remote organs are incompletely understood. Inhaled NO may exert systemic effects via interaction with circulating bone-marrow-derived cells (e.g., leukocytes) as they transit the lungs. Alternatively, some NO, once inhaled, may escape scavenging by hemoglobin and be converted to relatively stable NO-metabolites (e.g., nitrite, $\mathrm{S}$-nitrosothiols) that can regenerate $\mathrm{NO}$ in the periphery and directly protect neurons $[28,29]$. In the current study, we observed that iNO prevented cardiac arrest-induced increase of blood glucose levels. Elevated glucose serum levels seen in survivors of cardiac arrest have been identified as a predictor of adverse clinical outcomes following resuscitation [30-33]. While glucose serves as a marker of post-aggression metabolism and therefore, the degree of ischemia-reperfusion injury, glucose per se may harm the organism when reaching excessively high levels. Nonetheless, how iNO prevented the rise of glucose levels after CA (Cardiac arrest) is currently unknown. Mechanisms responsible for the protective effects of iNO in remote organs remain to be determined in future studies.

In this investigation, we observed significantly lower serum levels of S-100 protein in iNO-treated animals, suggesting neuroprotective effects of iNO. Nonetheless, although we saw improved clinical outcomes in iNOtreated animals, we failed to detect histological evidence that supports iNO-mediated neuroprotection. This is likely to be due to the limited sample size and limited number of animals surviving until day 5 of the follow up period. It is also likely that we failed to detect significant improvement in survival during the observation period due to the small sample size and high mortality rate.

\section{Limitations}

There are limitations when interpreting the results of our study: first, iCPR is a technique not frequently used in clinical emergency medicine and may not produce the same hemodynamic effects as chest compression CPR. Therefore, our results may not be readily transferable to settings in which chest compressions are used to perform CPR. On the other hand, use of the iCPR device enabled standardization of the quality of CPR, thus revealing the important beneficial effects of iNO in our unique model of cardiac arrest. This study was conducted in healthy, juvenile animals. Therefore, the effects of iNO may be different in human cardiac arrest patients with multiple comorbidities. While our current study was not designed to examine the optimal dose or timing of iNO administration, it is notable that the response to iNO to prevent I/R injury is similar across multiple species including man $[7,24,25]$. Further studies examining the effects of iNO during chest compression CPR, and optimal dose and timing of administration, are therefore warranted.

\section{Conclusions}

In summary, the current study showed that iNO augments pLVAD flow during iCPR, leading to better hemodynamics and improved clinical outcomes in a large-animal model of cardiac arrest. The beneficial effects of iNO may not solely depend on the improved pLVAD flow, but may also be mediated via direct neuroprotective effects of iNO in the post-arrest period. Currently, there is no pharmacological therapy that is known to improve outcomes after cardiac arrest. Along with accumulating evidence of the protective effects of iNO after $I / R$ injury including cardiac arrest, this first large-animal study should provide a solid foundation to translate this unique therapy to improve outcomes after cardiac arrest in patients.

\section{Key messages}

- iNO facilitates transpulmonary blood flow during iCPR

- Using 20 ppm iNO improves clinical outcomes after CPR in pigs

- Optimal dosing and timing needs to be verified in time-course and dose-response experiments

\section{Abbreviations}

ANOVA: analysis of variance; $\mathrm{AU}$ : arbitrary units; BL: baseline; $\mathrm{CA}$ : cardiac arrest; $\mathrm{CeSO}_{2}$ : cerebral oxygenation; $\mathrm{CO}$ : cardiac output; $\mathrm{CO}_{2}$ : carbon dioxide; CPP: coronary perfusion pressure; CPR: cardiopulmonary resuscitation; ECLS: extracorporeal life support; ECMO: extracorporeal membrane oxygenation; eCPR: extracorporeal CPR using ECMO; ELISA: enzyme-linked immunosorbent assay; et $\mathrm{CO}_{2}$ : end-tidal carbon dioxide; $\mathrm{F}_{2} \mathrm{O}_{2}$ : inspired oxygen fraction; HR: heart rate; iCPR: intravascular cardiopulmonary resuscitation; iNO: inhaled nitric oxide; LANUV: Landesamt für Natur, Umwelt und Verbraucherschutz NRW; MAP: mean arterial pressure; $\mathrm{mmHg}$ : millimeter of mercury; MPAP: mean pulmonary artery pressure; MTH: mild therapeutic hypothermia; $\mathrm{O}_{2}$ : oxygen; OPC: overall performance categories; $\mathrm{P}_{\mathrm{a}} \mathrm{CO}_{2}$ : arterial carbon dioxide tension; $\mathrm{P}_{2} \mathrm{O}_{2}$ : arterial oxygen tension; PAP: pulmonary artery pressure; $\mathrm{PCO}_{2}$ : carbon dioxide tension; PCWP: pulmonary capillary wedge pressure; ppm: parts per million; PVR: pulmonary vascular resistance; ROSC: return of spontaneous circulation; SD: standard deviation; SEM: standard error of the mean; SGC: soluble guanylate cyclase; VF: ventricular fibrillation.

\section{Competing interests}

MD received institutional funds from RWTH Aachen University and a grant provided by Abiomed Europe GmbH. Christoph Nix is an employee of Abiomed Europe $\mathrm{GmbH}$. For the remaining authors none were declared.

\section{Authors' contributions}

MD conceived of the study and its design, carried out the experiments, participated in the data acquisition, analyzed and interpreted the data and drafted the manuscript. AE carried out the experiments, helped to perform the immunoassays, participated in the data acquisition, helped to analyze the data and revised the manuscript. KWN prepared the cerebral tissue for examination, performed the neurohistopathological analysis, discussed the results and helped to revise the manuscript. JW, RR and FI participated in the study design, helped to interpret the data and revised the manuscript 
critically. CN carried out the experiments, participated in the data acquisition, helped to interpret the data and revised the manuscript critically. MF conceived of the study, participated in its design and coordination, analyzed and interpreted the data and helped to revise the manuscript. $A B$ participated in the design of the study, performed the statistical analysis and helped to revise the manuscript. All authors read and approved the final manuscript.

\section{Acknowledgements}

This work was made possible by a grant by the German Research Foundation (Deutsche Forschungsgemeinschaft: DE 1685/3-1) to Matthias Derwall and a grant to Michael Fries by the Else Kröner-Fresenius-Foundation (EKFS: 2014_A119). Fumito Ichinose was supported by the National Institutes of Health grant NIH R01 110378 (Matthias Derwall, Andreas Ebeling, Rolf Rossaint, and Anne Brücken).

\section{Author details}

'Department of Anesthesiology, University Hospital RWTH Aachen, Pauwelsstr. 30, 52074 Aachen, Germany. ${ }^{2}$ Institute for Neuropathology, University Hospital RWTH Aachen, Pauwelsstr. 30, 52074 Aachen, Germany. ${ }^{3}$ Anesthesia Center for Critical Care Research, Department of Anesthesia, Critical Care, and Pain Medicine, Massachusetts General Hospital and Harvard Medical School, 55 Fruit Street, Boston, MA 02114, USA. ${ }^{4}$ Abiomed Europe GmbH, Neuenhofer Weg 3, D-52074 Aachen, Germany. ${ }^{5}$ Department of Anesthesiology, St. Vincenz Hospital Limburg, Auf dem Schafsberg, 65549 Limburg, Germany.

\section{Received: 9 July 2015 Accepted: 26 August 2015} Published online: 15 September 2015

\section{References}

1. Field JM, Hazinski MF, Sayre MR, Chameides L, Schexnayder SM, Hemphill R, Samson RA, Kattwinkel J, Berg RA, Bhanji F, et al. Part 1: executive summary: 2010 American Heart Association Guidelines for Cardiopulmonary Resuscitation and Emergency Cardiovascular Care. Circulation. 2010;122:S640-656

2. Derwall M, Brücken A, Bleilevens $C$, Ebeling A, Fohr P, Rossaint R, Kern KB, Nix C, Fries M. Doubling survival and improving clinical outcomes using a left ventricular assist device instead of chest compressions for resuscitation after prolonged cardiac arrest: a large animal study. Crit Care. 2015;19:123.

3. Ichinose F, Roberts JD, Jr., Zapol WM. Inhaled nitric oxide: a selective pulmonary vasodilator: current uses and therapeutic potential. Circulation. 2004;109:3106-3111.

4. Zapol WM. Life at the frontier: the third annual John W. Severinghaus lecture on translational science. Anesthesiology. 2011; 114:771-781.

5. Hataishi R, Rodrigues AC, Neilan TG, Morgan JG, Buys E, Shiva S, Tambouret $R$, Jassal DS, Raher MJ, Furutani E, et al. Inhaled nitric oxide decreases infarction size and improves left ventricular function in a murine model of myocardial ischemia-reperfusion injury. American Journal of Physiology Heart and Circulatory Physiology. 2006;291:H379-H384.

6. Liu X, Huang Y, Pokreisz P, Vermeersch P, Marsboom G, Swinnen M, Verbeken E, Santos J, Pellens M, Gillijns H, et al. Nitric oxide inhalation improves microvascular flow and decreases infarction size after myocardial ischemia and reperfusion. J Am CollCardiol. 2007;50:808-817.

7. Lang JD, Jr., Teng X, Chumley P, Crawford JH, Isbell TS, Chacko BK, Liu Y, Jhala N, Crowe DR, Smith AB, et al. Inhaled NO accelerates restoration of liver function in adults following orthotopic liver transplantation. J Clin Invest. 2007;117:2583-2591.

8. Lovich MA, Pezone MJ, Wakim MG, Denton RJ, Maslov MY, Murray MR, Tsukada H, Agnihotri AK, Roscigno RF, Gamero LG, et al. Inhaled Nitric Oxide Augments Left Ventricular Assist Device Capacity by Ameliorating Secondary Right Ventricular Failure. ASAIO journal. 2015; 61:379-385

9. Derwall M, Timper A, Kottmann K, Rossaint R, Fries M. Neuroprotective effects of the inhalational anesthetics isoflurane and xenon after cardiac arrest in pigs. Crit Care Med. 2008;36:S492-495.

10. Fries M, Nolte K, Demir F, Kottmann K, Timper A, Coburn M, Weis J, Rossaint R. Neurocognitive performance after cardiopulmonary resuscitation in pigs. Crit Care Med. 2008;36:842-847.

11. Fries M, Nolte KW, Coburn M, Rex S, Timper A, Kottmann K, Siepmann K, Hausler M, Weis J, Rossaint R. Xenon reduces neurohistopathological damage and improves the early neurological deficit after cardiac arrest in pigs. Crit Care Med. 2008;36:2420-2426.

12. Fries M, Brücken A, Cizen A, Westerkamp M, Lower C, Deike-Glindemann J, Schnorrenberger NK, Rex S, Coburn M, Nolte KW et al. Combining xenon and mild therapeutic hypothermia preserves neurological function after prolonged cardiac arrest in pigs. Crit Care Med. 2012:40:1297-1303.

13. Niemann JT, Rosborough JP, Ung S, Criley JM. Coronary perfusion pressure during experimental cardiopulmonary resuscitation. Ann Emerg Med. 1982;11:127-131.

14. Baim DS, Grossman W: Grossman's cardiac catheterization, angiography, and intervention, 7th edn. Philadelphia: Lippincott Williams \& Wilkins; 2006.

15. Argenziano M, Choudhri AF, Moazami N, Rose EA, Smith CR, Levin HR, Smerling AJ, Oz MC. Randomized, double-blind trial of inhaled nitric oxide in LVAD recipients with pulmonary hypertension. The Annals of thoracic surgery. 1998;65:340-345.

16. Chandra NC, Tsitlik JE, Halperin HR, Guerci AD, Weisfeldt ML. Observations of hemodynamics during human cardiopulmonary resuscitation. Crit Care Med. 1990;18:929-934.

17. Ornato JP, Ryschon TW, Gonzalez ER, Bredthauer JL. Rapid change in pulmonary vascular hemodynamics with pulmonary edema during cardiopulmonary resuscitation. Am J Emerg Med. 1985;3:137-142.

18. Einav S, Kaufman N, Algur N, Strauss-Liviatan N, Kark JD. Brain biomarkers and management of uncertainty in predicting outcome of cardiopulmonary resuscitation: a nomogram paints a thousand words. Resuscitation. 2013;84:1083-1088.

19. Derwall M, Stoppe C, Brücken D, Rossaint R, Fries M. Changes in S-100 protein serum levels in survivors of out-of-hospital cardiac arrest treated with mild therapeutic hypothermia: a prospective, observational study. Crit Care. 2009;13:R58.

20. Minamishima S, Kida K, Tokuda K, Wang H, Sips PY, Kosugi S, Mandeville JB, Buys ES, Brouckaert P, Liu PK, et al. Inhaled nitric oxide improves outcomes after successful cardiopulmonary resuscitation in mice. Circulation. 2011; 124:1645-1653.

21. Terpolilli NA, Kim S-W, Thal SC, Kataoka H, Zeisig V, Nitzsche B, Klaesner B, Zhu C, Schwarzmaier S, Meissner L, et al. Inhalation of Nitric Oxide Prevents Ischemic Brain Damage in Experimental Stroke by Selective Dilatation of Collateral Arterioles. Circulation Research. 2012;110:727-738.

22. Li YS, Shemmer B, Stone E, M AN, Jonas S, Quartermain D. Neuroprotection by inhaled nitric oxide in a murine stroke model is concentration and duration dependent. Brain Res. 2013;1507:134-145.

23. Charriaut-Marlangue C, Bonnin P, Gharib A, Leger PL, Villapol S, Pocard M, Gressens P, Renolleau S, Baud O. Inhaled nitric oxide reduces brain damage by collateral recruitment in a neonatal stroke model. Stroke. 2012;43:3078-3084.

24. Nagasaka Y, Buys ES, Spagnolli E, Steinbicker AU, Hayton SR, Rauwerdink KM, Brouckaert P, Zapol WM, Bloch KD. Soluble guanylate cyclase-alpha1 is required for the cardioprotective effects of inhaled nitric oxide. Am J Physiol Heart Circ Physiol. 2011;300:H1477-1483.

25. Nagasaka Y, Fernandez BO, Garcia-Saura MF, Petersen B, Ichinose F, Bloch KD, Feelisch M, Zapol WM. Brief periods of nitric oxide inhalation protect against myocardial ischemia-reperfusion injury. Anesthesiology. 2008; 109:675-682.

26. Mathru M, Huda R, Solanki DR, Hays S, Lang JD. Inhaled nitric oxide attenuates reperfusion inflammatory responses in humans. Anesthesiology. 2007; 106:275-282.

27. Ng ES, Jourd'heuil D, McCord JM, Hernandez D, Yasui M, Knight D, Kubes P. Enhanced S-nitroso-albumin formation from inhaled NO during ischemia/ reperfusion. Circ Res. 2004; 94:559-565.

28. Cannon RO, 3rd, Schechter AN, Panza JA, Ognibene FP, Pease-Fye ME, Waclawiw MA, Shelhamer JH, Gladwin MT. Effects of inhaled nitric oxide on regional blood flow are consistent with intravascular nitric oxide delivery. J Clin Invest. 2001; 108:279-287.

29. Mullner M, Sterz F, Binder M, Schreiber W, Deimel A, Laggner AN. Blood glucose concentration after cardiopulmonary resuscitation influences functional neurological recovery in human cardiac arrest survivors. J Cereb Blood Flow Metab. 1997; 17:430-436.

30. Kim SH, Choi SP, Park KN, Lee SJ, Lee KW, Jeong TO, Youn CS, Korean Hypothermia Network I. Association of blood glucose at admission with outcomes in patients treated with therapeutic hypothermia after cardiac arrest. Am J Emerg Med. 2014; 32:900-904.

31. Daviaud F, Dumas F, Demars N, Geri G, Bougle A, Morichau-Beauchant T, Nguyen YL, Bougouin W, Pene F, Charpentier J et al. Blood glucose level 
and outcome after cardiac arrest: insights from a large registry in the hypothermia era. Intensive Care Med. 2014; 40:855-862.

32. Losert H, Sterz F, Roine RO, Holzer M, Martens P, Cerchiari E, Tiainen M, Mullner M, Laggner AN, Herkner $\mathrm{H}$ et al. Strict normoglycaemic blood glucose levels in the therapeutic management of patients within $12 \mathrm{~h}$ after cardiac arrest might not be necessary. Resuscitation. 2008; 76:214-220.

33. Nurmi J, Boyd J, Anttalainen N, Westerbacka J, Kuisma M. Early increase in blood glucose in patients resuscitated from out-of-hospital ventricular fibrillation predicts poor outcome. Diabetes care. 2012; 35:510-512.

\section{Submit your next manuscript to BioMed Central} and take full advantage of:

- Convenient online submission

- Thorough peer review

- No space constraints or color figure charges

- Immediate publication on acceptance

- Inclusion in PubMed, CAS, Scopus and Google Scholar

- Research which is freely available for redistribution 